the control group on this trial. This isolation effect was significant, $\mathrm{t}(200)=3.02, \mathrm{p}<.01$.

While treatments were again the same for experimental and control groups on the post-isolation trials, 10 through 12 , these trials were analyzed to determine if there were any residual effects from the previous isolation. Though from examination of Fig. 1, one might consider the experimental group to have slightly better STM on Trial 11 than the control group, ANOVA on the three post-isolation trials indicated that the groups and trials effects as well as their interaction were not significant, $p>.10$ in all three cases. Therefore, any apparent differences on post-isolation trials were attributed to chance factors.

When a more lenient criterion of STM, number of correct letters irrespective of their positions, was used, similar results were obtained throughout.

\section{DISCUSSION}

The results of the present experiment demonstrate that perceptually isolating an item increases its STM. Turvey \& Egan (1969), in a similar experiment, using slide area as the means of perceptual isolation, a $10-\mathrm{sec}$ recall period, and no post-isolation trials, also found improved STM for perceptually isolated items, lending further support for the present finding. Unfortunately, Turvey and Egan's measure of STM is questionable. A score of 2 was given to each letter of the $\mathrm{CCC}$ in its correct position and a score of 1 to each correct letter in an incorrect position. This assumes equivalence between one letter in its correct position (score $=2$ ) and two letters in incorrect positions ( assumption that would be difficult to justify. Furthermore, while this measure allows scores ranging from 0 to 6 , a score of 5 is impossible, raising some question about the scale.

Increasing the saliency of an item through perceptual isolation facilitates STM of that item. It is possible that better STM of an item involving a sudden change in conceptual class might also be attributable to increased attention to that item, rather than to a reduction of semantic interference effects from previous items. If this were the case, the findings of improved STM for an item differing in conceptual class from previously presented items (e.g., Loess, 1968; Wickens \& Ekler, 1968; Wickens \& Simpson, 1968) could easily be reconciled with findings of little or no semantic interference effects in STM (e.g., Baddeley, 1964; Baddeley, 1966: Gumenik, 1969).

A further finding of the present experiment was that there was no significant differences of isolating an item on the STM of post-isolation items. This may be analogous to the failure of several, but not all, investigators to find effects of stimulus isolation on non-isolated items (e.g., Gumenik \& Levitt, 1968).

The present STM task differed greatly from the usual serial or paired-associate learning situation in which isolation effects are found in that the present task did not involve repetition of the same items over several trials. Also, the present STM task involved the discrete recall of individual items rather than the learning of an entire list of items simultaneously. However, the similarity of isolation effects in the present STM task and in serial and paired-associate learning suggest that the same mechanism may be involved. One possible mechanism that might be operating in these disparate tasks could be akin to the "attention-getting value" of the isolated item suggested by Green (1958), which might enhance both STM of the item and the learning of the item in the repeated trials of a serial or paired-associate task.

\section{REFERENCES}

BADDELEY, A. D. Semantic and acoustic similarity in short-term memory. Nature, 1964. 204, 1116-1117.

BADDELEY, A. D. Short-term memory for word sequences as a function of acoustic, semantic and formal similarity. Quarterly Journal of Experimental Psychology, 1966, 18, 362-365. GRFEN, R. T. The attention-getting value of structural change. British Journal of Psychology, 1958,49,311-314.

GLMENIK. W. E. Effects of articulatory activity and auditory, visual and semantic similarity on the short-term memory of visually presented paired associates. Journal of Experimental Psychology. 1969, 82, 70-74.

GUMENIK, W. E., \& LEVITT, J. The von Restorff effect as a function of difference of the isolated item. American Journal of Psychology, 1968, 81, 247-252.

LOESS, H. Short-term memory and item similarity. Journal of Verbal Learning \& Verbal Behavior, 1968, 7, 87-92.

TURVEY. M. T., \& EGAN, J. Contextual change and release from proactive interference in short-term verbal memory. Joumal of Experimental Psychology, 1969, 81, 396-397.

UNDERWOOD, B. J., \& SCHULZ, R. W. Meaningfulness and verbal learning. Chicago: Lippincott, 1960.

WICKENS, D. C., \& EKLER, M. R. Semantic as opposed to acoustic encoding in STM. Psychonomic Science, 1968, 12,63.

WICKENS, D. D., \& SIMPSON, H. K. Semantic vs. phonetic encoding in short term memory. Paper presented at the meeting of the Midwestern Psychological Association, St. Louis, 1968

1. The authors wish to thank Patricia Mundelius for her assistance in computing the data.

\title{
Age changes in the Poggendorff illusion as measured by a method of production
}

\section{A. W. PRESSEY $Y^{l}$ and O. SWEENEY, University of Manitoba, Winnipeg 19, Canada}

Children at three age levels were tested on the Poggendorff illusion with a method of production. The illusion decreased with age; this supports previous investigations in which the method of adjustment was used. A sex difference of marginal significance was found, but the illusion did not change as a function of successive trials. It was concluded that the method of production is a valid means of measuring the Poggendorff illusion.

If two portions of a single oblique line are interrupted by two separate parallel lines, the two obliques do not appear collinear. Such a configuration is known as the Poggendorff illusion and is illustrated in Fig. $1 \mathrm{~A}$.

Traditionally, the method of adjustment has been employed to measure the illusion, but recently a method of production has been employed (Pressey \& Sweeney, 1969). Here, one of the obliques is removed, as shown in Fig. 1B, and $S$ is required to place a dot on the right vertical line so that the oblique on the left appears to point to it. There are several advantages to the method of production. First, complex, bulky and expensive equipment is not required. Second, the time necessary to test a $S$ is greatly reduced, and finally, the production method might easily lend itself to group testing. The major question

A

B

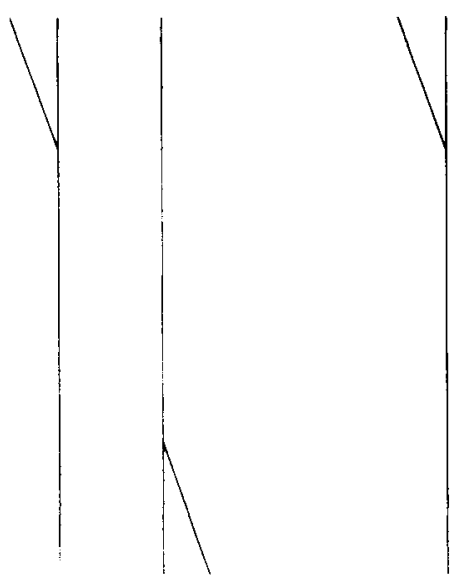

Fig. 1. The classical version (A) and a variation-(B) of the Poggendorff illusion. 
that remains, however, is whether or not the same functional relationships are obtained as with other psychophysical methods.

The purpose of this study was to determine the relationship between chronological age and the Poggendorff illusion. Leibowitz \& Gwozdecki (1967) and Vurpillot (1957), both employing the method of adjustment, reported a decrease in illusion as age increased from about 5 years to adulthood. The problem was to determine if the same relationship would be obtained with the method of production.

\section{METHOD}

The Ss were 46 boys and 54 girls who were selected randomly from Grades 3, 6, and 9 at the Pelly Trail School Division. 2 The mean ages of the groups were 8.6 $(\mathrm{N}=34), 11.8(\mathrm{~N}=33)$, and $14.6(\mathrm{~N}=33)$ years, respectively. There were 15,14 , and 17 boys in the three groups, respectively. None of the Ss was familiar with the illusion. Those Ss who normally wore glasses did so during testing.

The target holder, viewing distance, and the Poggendorff illusion were the same as described by Pressey \& Sweeney (1969). The practice card, however, was slightly different because the oblique on the left formed an angle of $80 \mathrm{deg}$ with the vertical line and joined that line 3.5 in. from the top.

The $S$ sat in front of the apparatus and was shown a practice card. The instructions explained that the task was to draw, on a given signal, a fine dot on the right vertical line at the point where the oblique line would join if it were extended. In a few cases with young children, it was necessary to have $S$ conceive of the oblique line as a road along which a car traveled. $S$ was then asked to indicate where the car would cross if it continued to travel in a straight line. After the response, $\mathrm{E}$ drew another oblique line with a red pencil. This line formed an angle of about $50 \mathrm{deg}$ with the vertical line and again joined it 3.5 in. from the top. $S$ then made a second response on the same card. If the second response was below the first, it was assumed that the task was understood. A second practice card was then given, and this was followed by the cards on which the Poggendorff configuration was drawn.

The instructions specified that only one choice on each target could be made, and that judgments were to be made visually, i.e., arm movements projecting the oblique were not allowed. Six trials were given, with each trial beginning as soon as the

Fig. 2. The Poggendorff illusion as a function of age. target was placed on the stand. After a 10-sec observation period, $\mathrm{E}$ signaled $\mathrm{S}$ to make the response.

\section{RESULTS AND DISCUSSION}

For each response, the position of the dot was subtracted from the POE to obtain a measure of the illusion. The results are shown in Fig. 2. An analysis of variance, in which the main effects were age, sex, and trials, was carried out. The $F$ value for age was $11.7(\mathrm{df}=2 / 94, \mathrm{p}<.01)$, and for sex it was $3.94(\mathrm{df}=1 / 94, \mathrm{p}=.05)$. None of the remaining $F$ ratios was significant at the .05 level. Omega-squared values (Hays, 1963 , p. 325) were also calculated, and for age, the value was .177 , while for sex, it was .024 . These values indicate that, whereas age contributed substantially to the total variance, the contribution of sex was minimal.

The presence of a sex difference found here is not supported either by Leibowitz \& Gwozdecki (1967) or Vurpillot (1957). Since sex accounted for so little of the variance, it is possible that the effect will prove not to be a reliable one. Hence, speculation on the reason for the sex difference may be premature.

One surprising result is that the illusion did not change with successive trials. This is the third study in which the method of production was used and the effect of successive trials was analyzed. In each study, the trend was different. Pressey \& Sweeney (1969) found a decrement in illusion as trials increased, and Pressey, Bayer, \& Kelm (1969) reported an inverted U-curve for both schizophrenic patients and a sample of nurses. Since the method used in all of these studies was substantially the same, it appears that the differences stem from the nature of the samples, viz, college students, schizophrenic patients, nurses, and children. It should be noted, in this regard, that most studies in the past that have been concerned with the effects of successive trials have used college students or trained Os. From the results reported here, it appears that the effects of successive trials on illusions should be investigated in diverse samples to ensure that conclusions are not limited to a particular type of sample.

The main finding of this investigation is that, with the method of production, the Poggendorff illusion decreases with age. This trend supports previous findings obtained with the method of adjustment, and consequently, it appears that the method of production is a valid technique for measuring the Poggendorff illusion.

\section{REFERENCES}

HAYES, W. L. Statistics for psychologists. New York: Holt, Rinehart and Winston, 1963.

LEIBOWITZ, H. W., \& GWOZDECKI, J. The magnitude of the Poggendorff illusion as a function of age. Child Development. 1967.38, 573-580.

PRESSEY, A. W., BAYER, C. A., \& KELM. H. The Poggendorff illusion in schizophrenic patients. Schizophrenia, 1969, 1. 88-94.

PRESSEY, A. W., \& SWEENEY, O. A variation of the Poggendorff illusion. Perceptual \& Motor Skills, 1969. 28. 883-886.

VURPILLOT, E. L'influence de la signification du materiel sur l'illusion de Poggendorff Annee Psychologique, 1957. 57, 339-357. NOTES

1. Requests for reprints should be sent to the Department of Psychology, University of Manitoba, Winnipeg 19, Manitoba, Canada.

2. We are indebted to $A$. Minish for his aid in making Ss available.

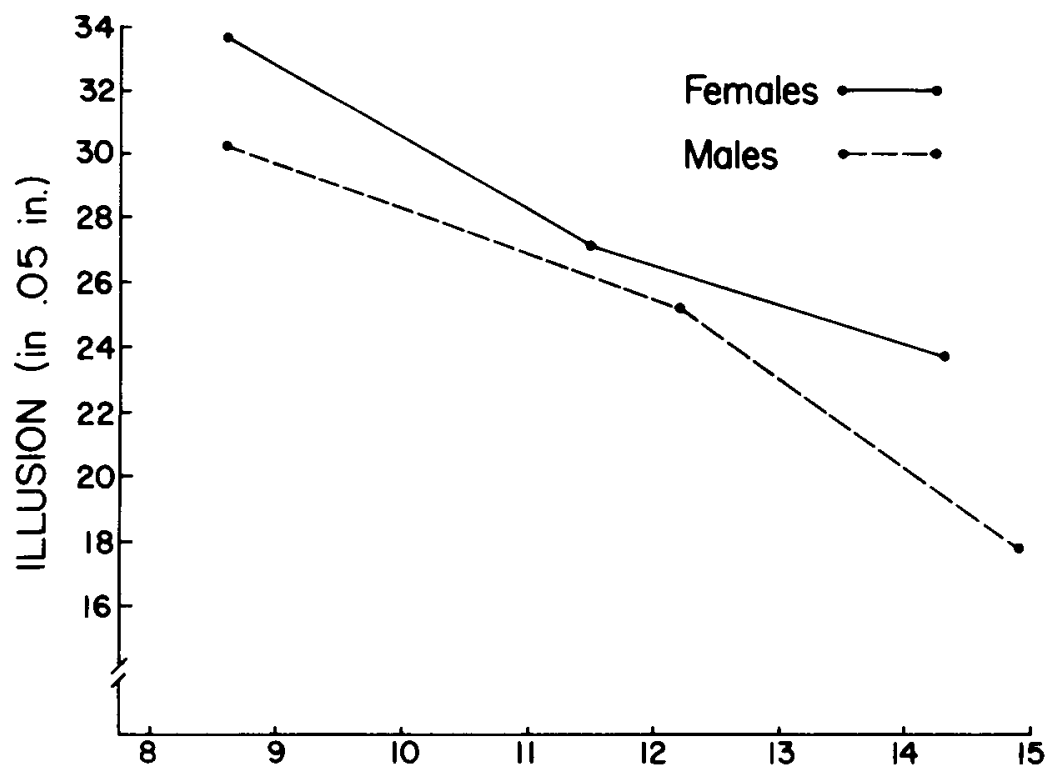

AGE 